\title{
CONFIDENCE: project description and main results
}

\author{
W. Raskob ${ }^{1, *}$, N.A. Beresford ${ }^{2}$, T. Duranova ${ }^{3}$, I. Korsakissok ${ }^{4}$, A. Mathieu ${ }^{4}$, M. Montero ${ }^{5}$, \\ T. Müller ${ }^{1}$, C. Turcanu ${ }^{6}$ and C. Woda ${ }^{7}$ \\ ${ }^{1}$ KIT - Karlsruhe Institute of Technology, Eggenstein-Leopoldshafen, Germany. \\ 2 CEH - UK Centre for Ecology \& Hydrology, Lancaster, United Kingdom. \\ ${ }^{3}$ VUJE-VUJE, a.s., Trnava, Slovak Republic. \\ ${ }^{4}$ IRSN-Institut for Radioprotection and Nuclear Safety, Fontenay-aux-Roses, France. \\ ${ }^{5}$ CIEMAT - Centro de Investigaciones Energéticas, Medioambientales y Tecnológicas, Madrid, Spain. \\ ${ }^{6}$ SCK-CEN-Belgian Nuclear Research Centre, Mol, Belgium. \\ 7 HMGU - Helmholtz Zentrum München-German Research Center for Environmental Health, Neuherberg, Germany.
}

\begin{abstract}
The project CONFIDENCE (COping with uNcertainties For Improved modelling and DEcision making in Nuclear emergenCiEs) performed research on identifying and reducing uncertainties in the release and post-release phases of an emergency. The project started in January 2017 as part of the European Joint Programme CONCERT. It brought together 31 partners from 18 countries and involved members of five European Radiation Protection Platforms namely ALLIANCE, EURADOS, MELODI, NERIS and SHARE. The work program included research on early phase modelling and monitoring considering weather, source term and monitoring uncertainties. Consideration of social, ethical and communication aspects was a key part of our activities. This comprised strategy development in the transition phase together with stakeholder interaction, understanding of the population and which uncertainties are relevant for decision-making. Finally, formal decision aiding techniques were investigated and tested.
\end{abstract}

Keywords: emergency management / uncertainties / decision support / CONFIDENCE

\section{Introduction}

Radiation Protection (RP) research has a long lasting tradition in the Euratom Framework. In Horizon 2020, the funding mechanisms changed and a European Joint Programming project was awarded to advance RP; the CONCERT ${ }^{1}$ project started in May 2015. A substantial part of the project resources were allocated to open calls to tackle highly ranked topics in RP research. Two calls were envisaged taking into account priorities defined by consultations with stakeholders, beneficiaries of CONCERT and the Radiation Protection Platforms. For the first call, two topics were identified:

1 Improvement of health risk assessment associated with low dose/dose rate radiation;

2 Reducing uncertainties in human and ecosystem radiological risk assessment and management in nuclear emergencies and existing exposure situations, including NORM.

\footnotetext{
*Corresponding author: wolfgang.raskob@kit .edu

${ }^{1}$ https://www.concert-h2020.eu/en.
}

Following the evaluation by external reviewers, three projects were funded, among them CONFIDENCE.

The key objective of CONFIDENCE was to understand and if possible reduce uncertainties relevant for decisionmaking in the threat, response and transition phases of an emergency (Fig. 1).

\section{Work plan}

The overall budget summed up to $6201026 €$ with an EC contribution of $3252487 €$. The rather low contribution of the EC shows the high importance of that topic as several organisations joined without receiving money from the EC. Starting first of January 2017, the project was completed by end of December 2019. Thirty-one partners from 18 countries contributed to the research deliverables (see Fig. 2).

CONFIDENCE aimed to improve decision-making for the protection of the population affected by nuclear emergencies and to minimise disruption of normal living conditions. This was to be achieved through the reduction of uncertainties, where practicable, and the development of approaches to deal with uncertainty information. CONFIDENCE used a 


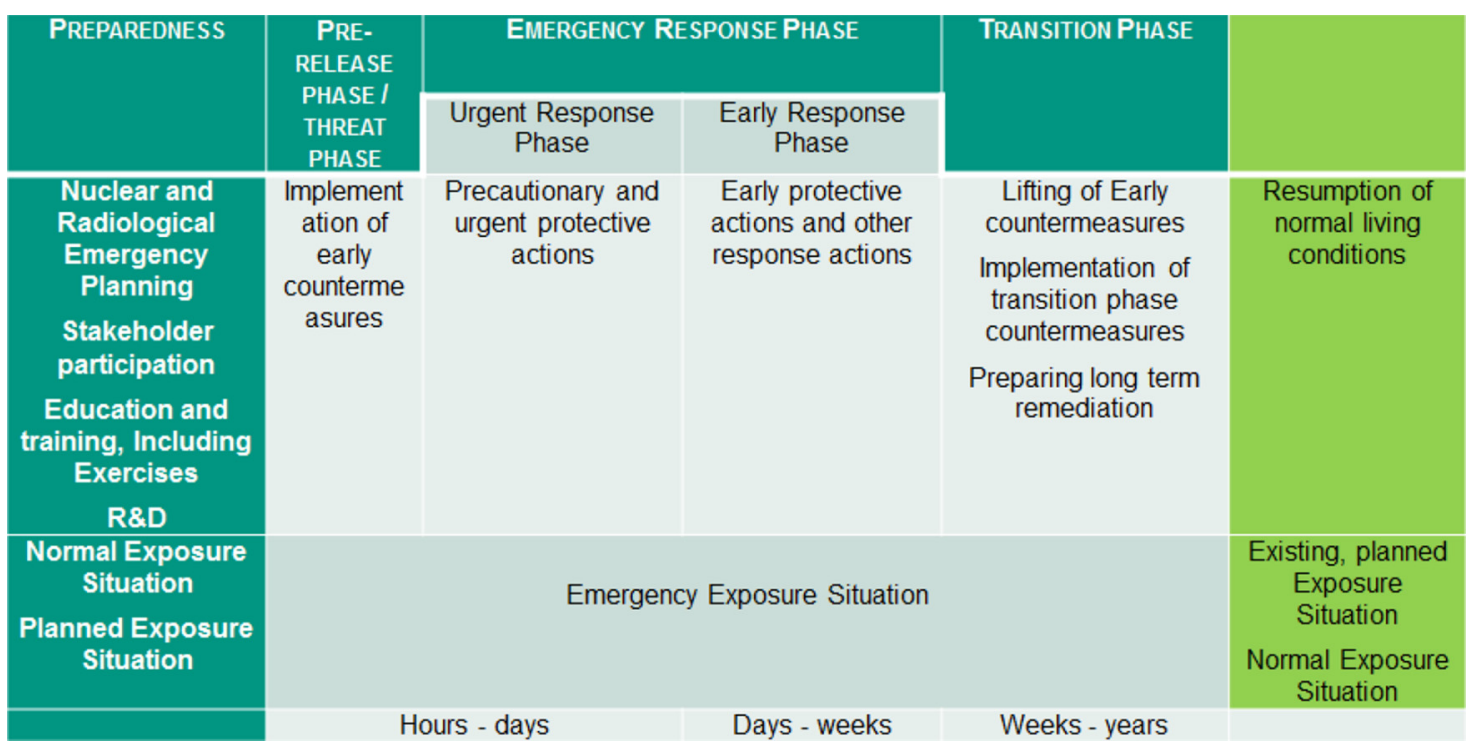

Fig. 1. Phases of a nuclear or radiological emergency (adapted from NERIS, 2019).

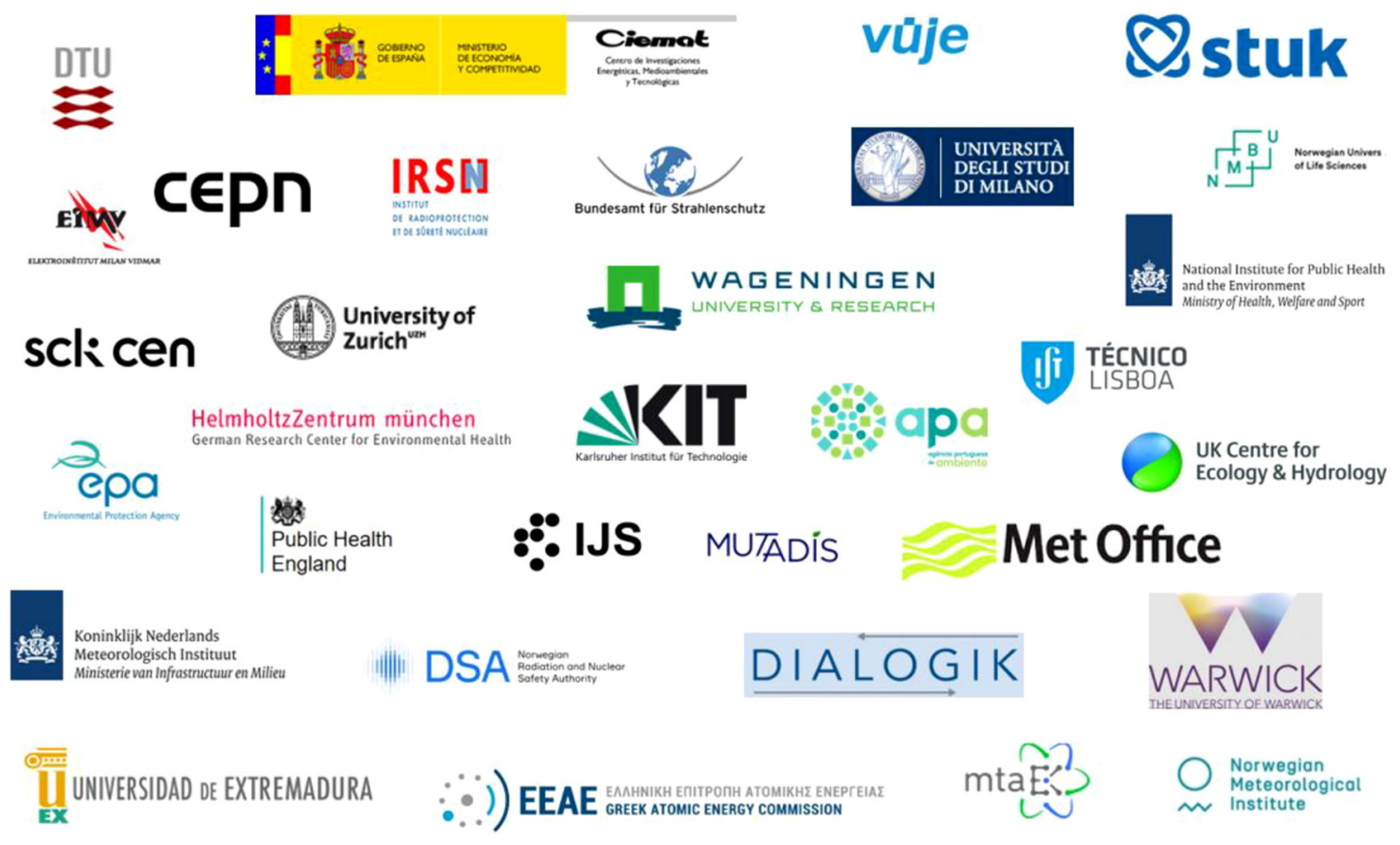

Fig. 2. CONFIDENCE partners.

multidisciplinary approach dealing with all aspects regarding the radiological situation following an accidental release, from the prognosis of dispersion and its spatial-temporal evolution, to the offsite consequences, and the decision making to select, implement and evaluate remediation strategies, including the viewpoints of stakeholders. There was an aim that some of the innovative software solutions to be developed by CONFIDENCE should be integrated into Decision Support Systems (DSS) for operational use in the nuclear emergency management. These revised DSS would then be used to develop scenarios key within CONFIDENCE's work plan. The project was subdivided into six interlinked work packages (WP), with an additional E\&T WP, to achieve the following objectives:

- Tackle uncertainties in the pre- and early release phase of the accident, by: (i) identifying and ranking the main sources of uncertainties; (ii) characterizing and quantifying their effect on simulation results (e.g., activity concentrations, dose assessment, reference levels); and (iii) proposing practical solutions to better take into account these uncertainties in an emergency response context (WP1);

- Develop comprehensive software tools for the quick and efficient assessment of cancer risk to affected populations 
to be used as an input in the overall decision making process (WP2);

- Develop approaches and tools integrating external and internal dosimetric monitoring data to obtain a comprehensive picture of the radiological situation and link it with dose simulations and risk assessment tools to support decision making (e.g. for medical screening needs) (WP2);

- Improve the capabilities of radioecological models used to predict activity concentrations in foodstuffs and to better characterise, and where possible, reduce uncertainties (WP3);

- Engage national stakeholders to improve the preparedness and response in the transition phase, and to identify and reduce the uncertainties in the subsequent management of the long-term exposure situation, reflecting requirements from the new European Basic Safety Standards (WP4);

- Identify social and ethical issues related to uncertainty management in emergency and post-accident situations and clarify how stakeholders at the various levels deal with uncertainty in their decision making processes (WP5);

- Support and improve communication of uncertainties (WP5 and WP6) and facilitate robust decision making taking into account the variability of the radiological situation and decision makers' preferences (WP6);

- Develop training courses and educational material for professionals and students related to the issues and activities addressed in CONFIDENCE (WP7).

With the identification and quantification of uncertainties in the early phase, we aim to propose for the first time a comprehensive methodology for managing them in the decision making process supported by enhanced DSS. Improved dose monitoring data together with their assimilation with simulation results might allow a better on-going analysis of the radiological situation. Risk assessments, in particular for critical groups, will support early estimation of the need for longer-term medical care and monitoring. Improved radioecological models should reduce uncertainties in predictions needed for developing management options for food production systems. The aim was for outputs of work packages $1-3$ to be integrated into a DSS where feasible during the course of the project.

\section{Challenges and opportunities}

When setting up the works program it became obvious that integration of the six research work packages was key for success (see Fig. 3).

Of particular importance was to link results achieved in the first three simulation based works packages (WPs) to the last three WPs that were mainly addressing methodological aspects but needed to use results from the first thee WPs. To deal with this early in the project, we used results from the first investigations as input to the discussions in WP4 to WP6. Another issue was the organisation of the national panels in WP4, WP5 and WP6. As topics were overlapping, e.g. the multi-criteria decision aiding (MCDA) approach under development in WP6, the panels of WP4 and WP5 should use results from WP1. The number of panels had to be discussed early in the project. Stakeholder resources are

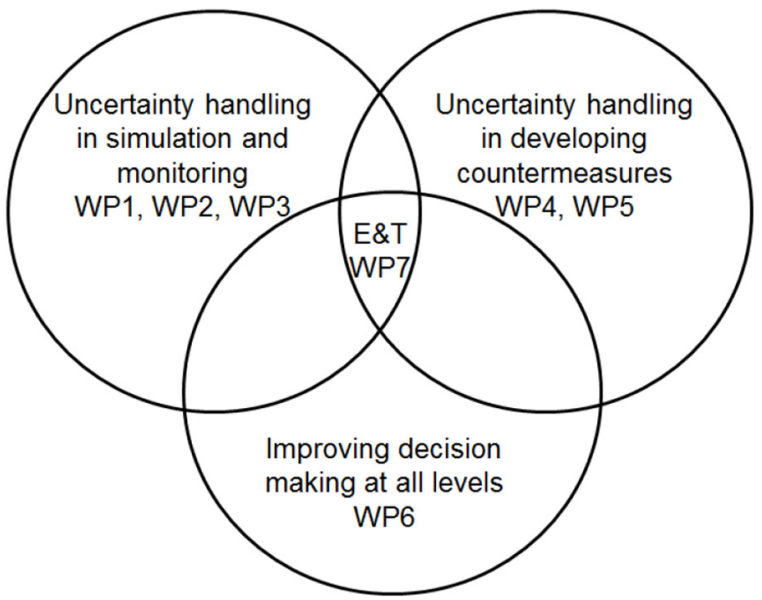

Fig. 3. Interdependencies of work packages of CONFIDENCE.

limited and we did not want willing stakeholders to be asked to participate in too many panels and meetings.

CONFIDENCE is a research project; research projects should improve preparedness and response to radiological and nuclear emergencies (needs that were clearly identified following the disasters of Chernobyl and Fukushima). JRODOS (see e.g. Ehrhardt and Weis, 2000; Ievdin et al., 2010) emerged from the European project EURANOS ${ }^{2}$ (2004 2009) and is now installed and operationally used in more than 20 countries worldwide. CONFIDENCE aimed to develop operational guidelines for practitioners and national institutions involved in emergency management and long-term rehabilitation. Simulation models and approaches developed within WP1-3 were implemented, at least as prototypes, in DSS (and tools that are applied at the national level).

As decision making in case of an emergency is very challenging, multidisciplinary research activities is crucial. CONFIDENCE brought together institutions from five RP platforms namely, ALLIANCE (http://www.er-alliance.eu/), EURADOS (http://www.eurados.org/), MELODI (http:// www.melodi-online.eu/), NERIS (http://www.eu-neris.net/), and SHARE. This allowed us to tackle the most important research questions in an integrated way. It also demonstrated the spirit of CONCERT to integrate the various RP platforms under one research project regarded as important by stakeholders, beneficiaries and scientists.

Before our project, uncertainties in the decision making processes (with respect to nuclear emergencies) were not seriously investigated. Sensitivity studies (see e.g. Tarsitano et al., 2005; Ikonen et al., 2012; Girarda et al., 2014) were performed in many disciplines and for many different simulation models used in the RP area. However, investigating the key uncertainties in the decision making process itself was not done. Integrating the many disciplines and numerous stakeholders from different levels (local to national and even international) gave us the opportunity to tackle the many facets of the problem. The large number of partners, stakeholders and RP platforms allowed immediate dissemination of our results. This was backed up by a comprehensive education and training program developed within works package 7 .

\footnotetext{
$\overline{{ }^{2} \text { https://euranos.iket.kit.edu/ }}$
} 
Notwithstanding the many challenges identified in the beginning of the project, the opportunities provided by CONFIDENCE, when accepted by the end users, have the potential to progress significantly decision-making in nuclear and radiological emergency management and long-term rehabilitation - when finally adopted by the end users.

\section{Main achievements}

This section briefly describes the main research questions and key findings aiming to direct the interested reader to the sections in this special issue that explain the results in much more detail.

\subsection{WP1 research questions}

The following research questions were addressed:

- What are the key drivers for uncertainties and how can they be handled in simulation models?

- Is the ensemble approach (realisation of a state by many simulations with slightly different initial conditions) appropriate to describe uncertainties from the key drivers and how can these uncertainties propagated through atmospheric dispersion to dose and food chain models?

- Does the application to hypothetical accidents in Europe (Norway, the Netherlands) show the benefit of our approach?

- What is the result when comparing the simulation models with data from the Fukushima accident?

- How do we use the ensemble approach in a timeframe compatible with emergency response?

\subsection{WP1 key findings}

The main findings can be summarised as follows (see S.J. Leadbetter et al., 2020 and follow on from section EARLY PHASE MODELLING):

- Key driver for uncertainties in the input data for atmospheric dispersion calculations are wind direction, atmospheric stability, source term, and start of release;

- The ensemble approach was used to describe uncertainties. Ensembles of numerical weather prediction (see Fig. 4) as well as ensembles of source terms were used in many different scenario calculations to estimate the uncertainty in air and ground concentration and dose results. Scenarios with contributions from up to seven model groups were executed for hypothetical accidents in Europe (Norway, the Netherlands);

- One exercise with comparison of model results with data from Fukushima demonstrated the applicability of the uncertainty bands;

- Results of the many ensemble runs were propagated through dose and foodchain calculations, and thus covering all key simulation components important for early decision-making;

- Operational guidelines were developed.

\subsection{WP2 research questions}

WP2 addressed the following questions:

- How to combine model results and monitoring information?

Can this be achieved via data assimilation approaches?

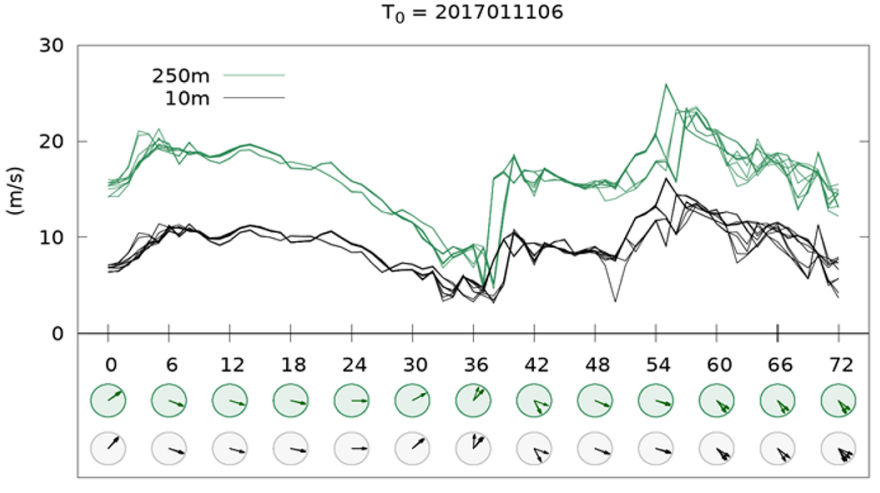

(h)

Fig. 4. Example meteorological ensembles representing wind speed at two heights $(10 \mathrm{~m}$ and $250 \mathrm{~m})$.

- What are the uncertainties in mobile and stationary monitoring systems and how do we improve monitoring strategies?

- Health risk assessments are not part of a DSS - but can this functionality be developed and made available early in an emergency?

- Are "Apps" that enable dose-rate measurements using the camera sensor of the smartphone fit for purpose?

- What are the key improvements needed for internal and external dosimetry?

- Can we apply biodosimetric approaches, primarily designed for high doses, with emergency response?

\subsection{WP2 key findings}

The main results can be briefly summarised as follows (see M. Bleher et al., 2020 and follow on from section UPDATED RADIOLOGICAL SITUATION):

- Combination of model results and monitoring information via data assimilation approaches is a promising method to improve the operational picture in the early phase;

- A model to support individual dose estimations has to be developed;

- A software for health risk assessment was developed taking into account the uncertainty of the dose estimation of the DSS or the uncertainty of the individual dose measurement technique. Results are available for decision-making but require further discussion on their usability;

- Apps that enable dose-rate measurements using the camera sensor of the smartphone have been evaluated in reference fields; only one seems to be appropriate for citizen monitoring;

- A prototype of a data processing unit for thyroid dose monitoring using a smartphone app has been developed;

- Sensitivity analysis associated to thyroid doses after intake of radioiodine completed;

- Electronic components in smartphones can be used to measure the dose due to external exposure ( $>20 \mathrm{mGy}$ );

- Workshop on biodosimetry and needs of emergency response was performed and recommendations developed (Fig. 5). 


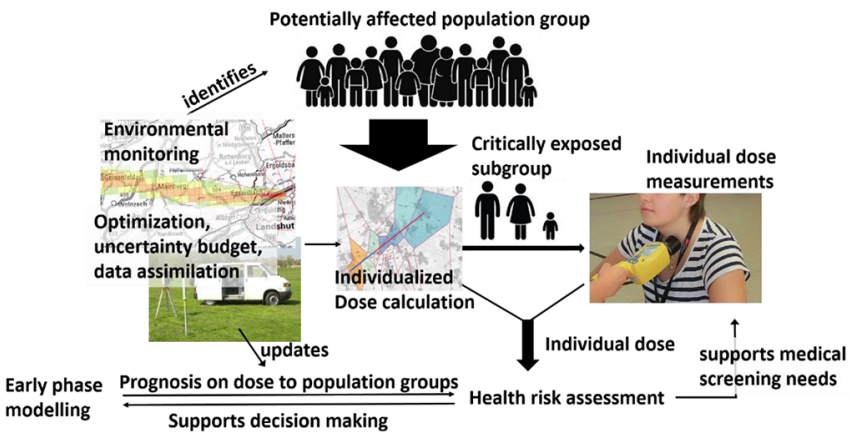

Fig. 5. Scheme to improve the operational picture and assessment of doses and risk to the population.

\subsection{WP3 research questions}

The following research questions were addressed in WP3:

- Is there a need for improving model databases, including through experimentation?

- Can we close gaps in the databases by using "phylogentic" models?

- Are soil-plant process-based models fit for purpose?

- How do we address radioactive (or "hot") particles in foodchain models?

\subsection{WP3 key findings}

The main findings can be summarised as follows (see N.A. Beresford et al., 2020 and follow on from section FOODCHAIN IMPROVEMENTS):

- Key parameters of operational radioecological models have been identified and data collected;

- Data for Mediterranean ecosystem have been collected;

- It was demonstrated, that root uptake for I-131 is not important;

- Process based models for strontium and caesium were developed and assessed and required improvements identified;

- Comparison between commonly used empirical ratio based radioecological models and soil-plant process-based models demonstrated the adequate performance of empirical models in the early phase of an emergency and the benefits of adopting process-based models in the longer-term when root uptake is the dominant process determining radionuclide activity concentrations in crops;

- The need to consider plant uptake from radioactive particles is minimal, however, not considering radioactive particles in the longer-term may underestimate dose (Fig. 6).

\subsection{WP4 research questions}

WP4 performed research on the following questions:

- Which type of uncertainties are important during the response management and planning for the recovery in the transition phase of a nuclear emergency?

- How to develop scenarios useful for the preparedness for the post-accident recovery that involves stakeholders in the decision making process?

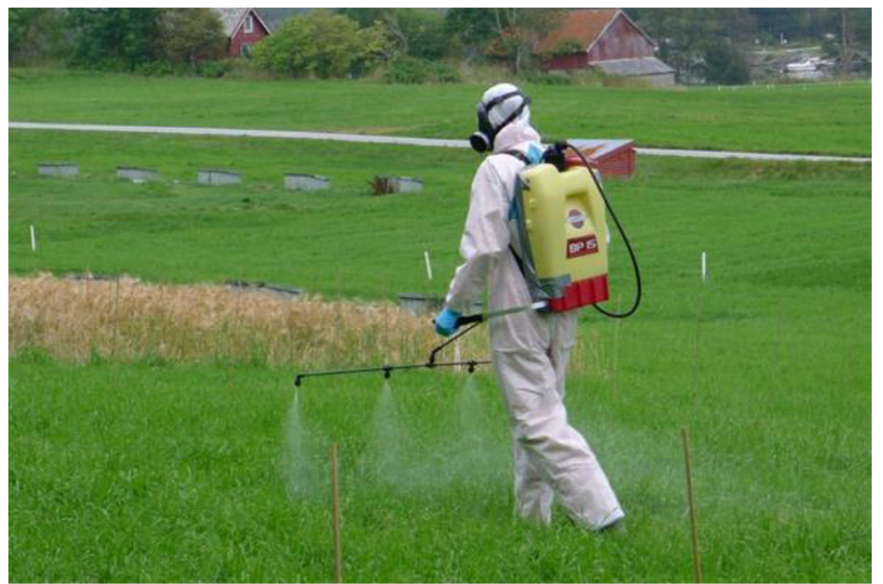

Fig. 6. Spraying ${ }^{131}$ I onto crops (Photo: NMBU).

- Do decision-oriented scenario-analysis allow identification, evaluation and optimisation of countermeasure strategies by involving stakeholders?

- How to identify important attributes and criteria for defining countermeasure strategies?

- Can we develop a "default" set of attribute/preference values that might be used in the decision making process with formal tools such as MCDA?

- What will be the recommendations and proposals for best practices in the decision making process from stakeholders' panels?

\subsection{WP4 key findings}

The main results can be summarised as (see $\mathrm{T}$. Charnock et al., 2020 and follow on from section DEVELOPMENT OF COUNTERMEASURE STRATEGIES INVOLVING STAKEHOLDERS):

- Greater understanding of the sources of uncertainties in model predictions of residual dose from external exposure of radionuclides deposited in the urban environment was achieved, allowing to develop recommendations for both the use of currents models (e.g. ERMIN) and also for their future development;

- A review and analysis of the uncertainties affecting the knowledge on the transfer and fate of radionuclides along different components of agricultural systems and their response to recovery actions was accomplished. Approaches to deal with such uncertainties and to provide maps and other information to help preparedness for the recovery were developed;

- Decision-oriented scenario-analysis clearly demonstrated its added value and allowed us to identify, evaluate and optimise countermeasure strategies by involving stakeholders (see Fig. 7);

- The workshops and the Delphi study with stakeholders from different European countries resulted in a set of preference values that could be used in formal decision aiding tools, in particular the MCDA;

- Recommendations were developed for different facets when developing strategies under uncertainties. 


\section{Objectives of the recovery}

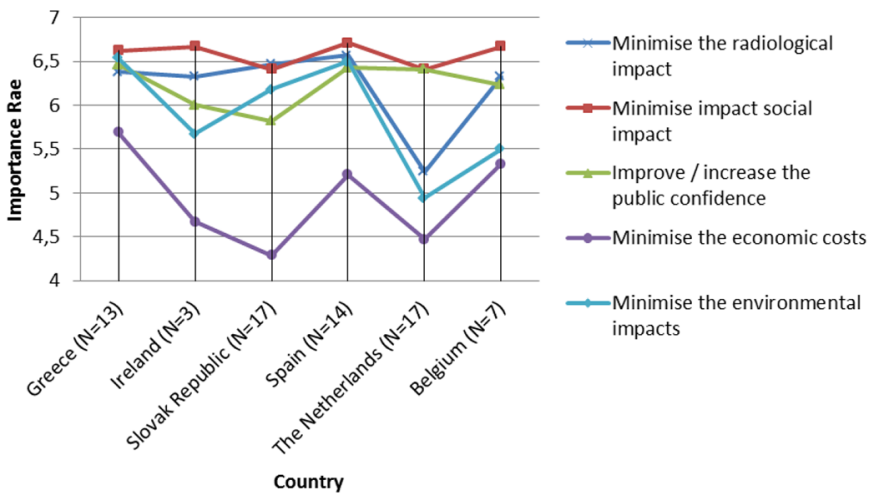

Fig. 7. Results from national stakeholders' surveys realised under the study Delphi related to the main objective of a recovery strategy.

\subsection{WP5 research questions}

The following questions were addressed by WP5:

- Can we identify social uncertainties from analysing past events (e.g. Chernobyl, Fukushima, Fleurus, Asco, Tricastin and Krsko)?

- What are the expected behaviour and information needs of the public?

- What can we learn from observing emergency exercises?

- Do mental models help us to understand the processing of uncertainties by experts and the general public?

- What are stakeholder preferences at the local level?

- What are key uncertainties when discussing strategies at the international level?

- How to best communicate uncertainties (e.g. maps, SMS text)?

\subsection{WP5 key findings}

The main results can be summarised as (see C. Turcanu et al., 2020 and follow on from section SOCIAL UNCERTAINTIES):

- Analysis of social uncertainties from past events was very useful to identify common patterns;

- Studies on expected behaviour and information needs demonstrated the need to refine emergency planning and communication to the public (see Fig. 8);

- Observation of emergency exercises identified key uncertainties that play a role in decision making of authorities and the general public;

- Development of mental models were useful to understand processing of uncertainties by different groups (e.g. population, experts);

- Studies on stakeholder preferences at local and international levels helped in defining "dignified living conditions";

- Probability maps in the early phase were appreciated by decision makers;

- Communication of uncertainties is important and some guidelines were derived.
Expected compliance with emergency actions: \% respondents who would definitely or probably carry out the action when advised to do

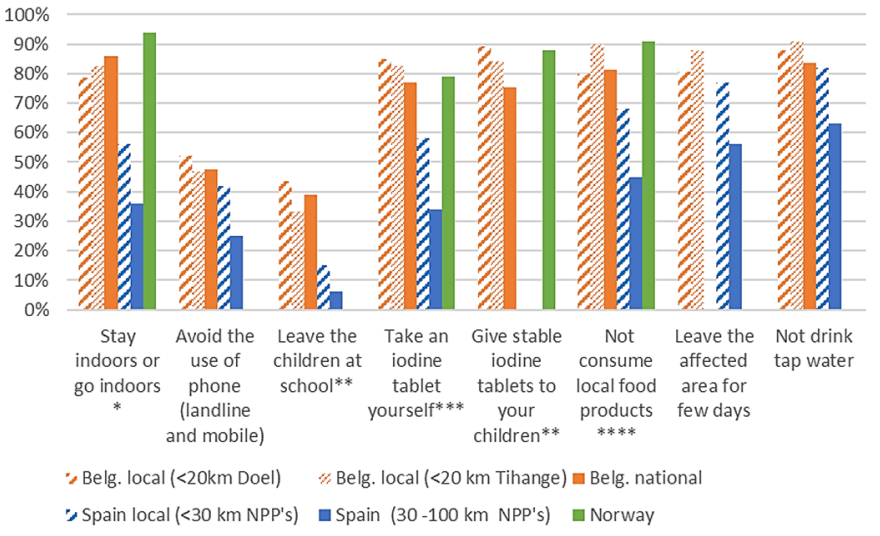

Fig. 8. Study on compliance with advice from authorities.

\subsection{WP6 research questions}

WP6 worked on the following questions:

- Can we expand formal decision aiding tools such as MCDA to deal with uncertain input?

- How to visualise uncertainties and identify output for a DSS as suitable for decision making?

- Is it possible to apply preferences and strategies, generated in other work packages, as input for the MCDA in decision making workshops?

- What is the benefit of Agent Based Simulation models $(\mathrm{ABM})$ ? Can they help to better understand the importance of the negotiation process?

- Which negotiation schemes can be implemented and is this possible to represent the negotiation process in different countries?

\subsection{WP6 key findings}

Main results can be summarised as follows (see S. French et al., 2020 and follow on from section DECISION MAKING UNDER UNCERTAINTIES):

- The MCDA tools was enhanced with uncertainty handling (see Fig. 9);

- Preferences and strategies, generated in other work packages were successfully applied to the MCDA in stakeholder workshops;

- Visualisation methods for presenting probability maps to decision makers were tested;

- Robustness indicators were developed to help decision makers in using appropriate results from a DSS;

- An ABM model was developed to investigate the decision making process in more detail;

- The ABM model was tested with different negotiation schemes to better understand the negotiation process resulting in priority setting by voting;

- It was also applied to different compositions of decision making teams as indicated by a set of European countries and allowed to study many aspects of composition of teams and preference negotiations. 


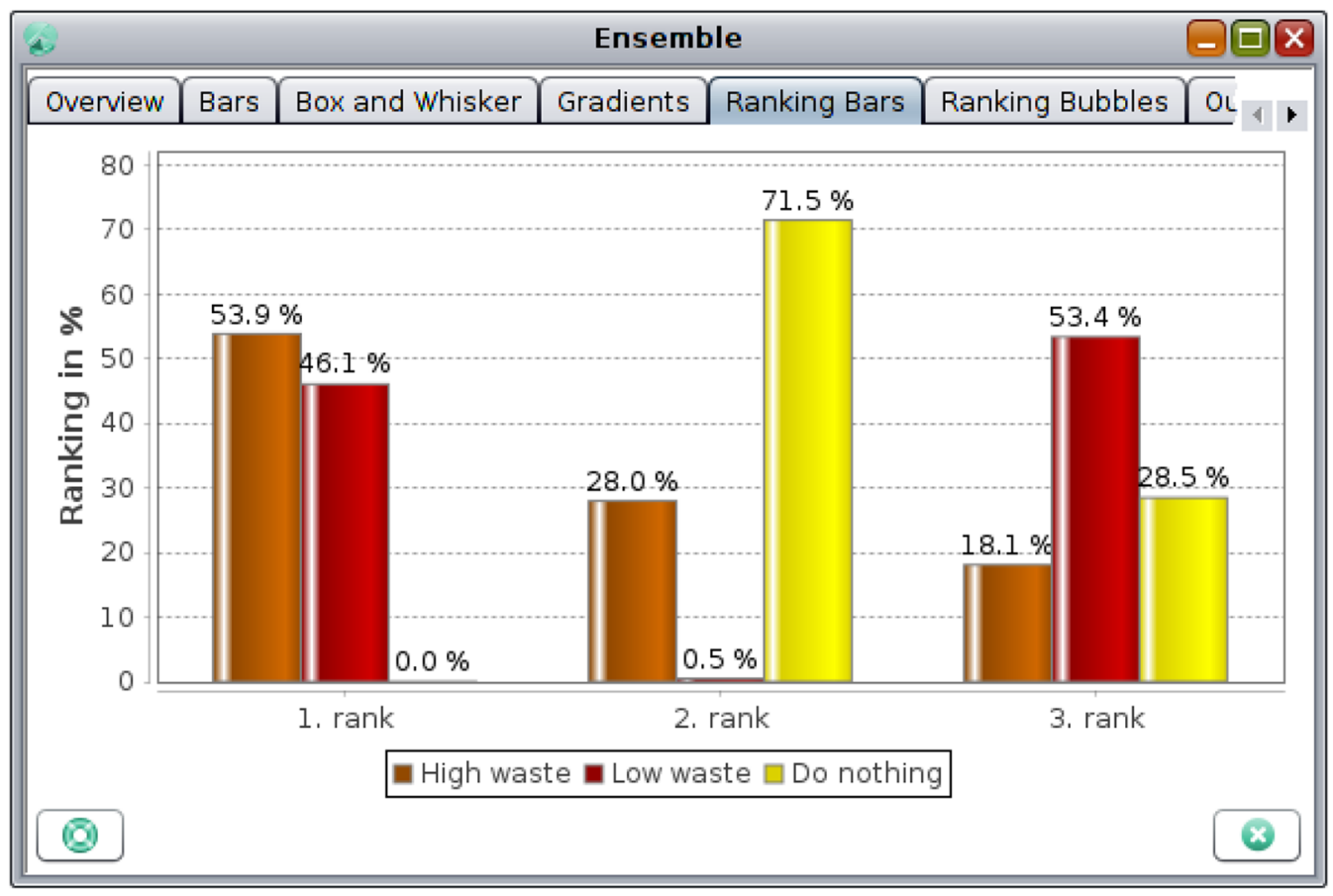

Fig. 9. Ranking of strategies with contribution of uncertainties of values and preferences.

An important aspect of CONFIDENCE was dissemination realised through WP7. Work performed there can be summarised as (see T. Duranova et al., 2020 from section CONFIDENCE):

- Development and performance of the training course "Use of uncertain information by decision makers at the various levels within the decision making process and its communication" (see Fig. 10);

- Development and performance of the workshop "Do process-based models have a role in human food chain assessments";

- Development and performance of the CONFIDENCE course "Communication under uncertainty: Nuclear or radiological emergencies, radiation protection and other issues important to know for your (future) occupation";

- Performance of the CONFIDENCE Dissemination workshop with 88 participants.

\section{Discussion and conclusions}

As discussed in the above, CONFIDENCE was a first attempt to deal with uncertainties in nuclear and radiological emergency management and long-term rehabilitation in a comprehensive way. We can state, that key uncertainties in the decision making process were addressed and methods identified that can improve the handling of uncertainties in the different phases of an emergency. Reducing "technical" uncertainties was regarded as important for parametrisation of models and using state of the art tools, insofar as they can help improve the understanding and awareness of the situation and issues at stake to be addressed in each phase of the emergency. Countermeasure strategy development with the help of scenarios and formalised approaches turned out

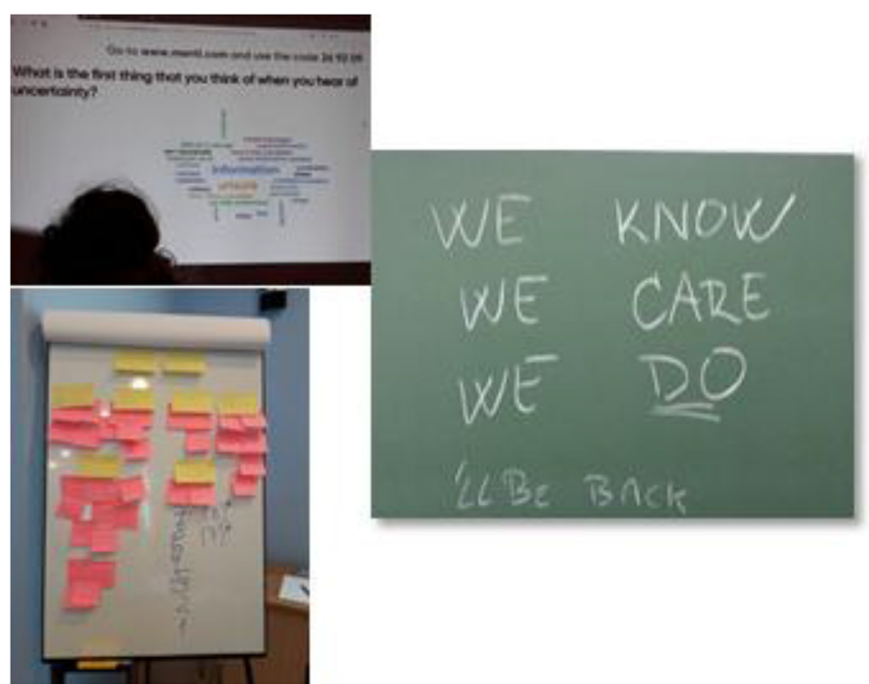

Fig. 10. Impression from training courses.

to be extremely valuable. National SH panels were very useful to investigate how stakeholders process all the information and confront with uncertainties, both technical and derived from the different views and preferences of the actors. In this sense, stakeholders' panels showed that dealing with uncertainty is not limited to try reducing it or eliminating, but need exploring and negotiate with actors involved the many possible ways of interpreting and solving the problem.

During the project, in particular during the many stakeholder panels, the need to reduce uncertainties was not considered a priority by many stakeholders. 
Identifying social and ethical uncertainties using observations, and mental and health behaviour models was a key to understand why messages and communication has to be framed in a particular way to assure, as far as possible, that advice is understood and recommendations followed. Communication of uncertainties in results of simulation models or via other means was tested.

To convert science into practice, operational guidelines and recommendations were developed that allow testing and integrating of our results in national procedures. Implementation of results from CONFIDENCE in the operational European JRodos system and national simulation platforms assure that they can be further tested and refined in the future. The MCDA tool that was developed here will be used in other international projects and is freely available for download ${ }^{3}$. This is needed as many of the approaches developed are new and end users require training. The integrated training program helped in this and disseminated key findings of the project to a wider community. The immediate link with the RP platforms allowed us to feed the results of CONFIDENCE into the further development of the respective Strategic Research Agendas of each platform.

We also have to state that CONFIDENCE has not solved all issues related to uncertainties in the decision making process. To illustrate this, we asked representatives of international organisations (IAEA and ICRP), RP platforms (ALLIANCE, EURADOS, NERIS, SHARE) and end users to provide their view on the project and further research needs. Finally, members of CONFIDENCE identified further research needs. More details on these recommendations can be found in the paper on "the way forward and research needs" (W. Raskob et al., 2020).

Key messages from international organisations

- Results obtained by CONFIDENCE and other related projects will be important inputs to IAEA projects;

- The international community should develop guidance based on lessons learned in research on how to engage stakeholders in decision making processes;

- CONFIDENCE is directly related to the ICRP recommendations on emergency exposure situations and existing exposure situations post-accident;

- Improvement in modelling and decision making clearly contributes to better implementation of the recommendations;

- The framework developed with the seven anthropologic criteria of dignified living conditions is aligned with ICRP values;

- The health risk assessment tool developed in CONFIDENCE could be used to inform risk under emergency exposure situation.

\section{Key messages from the platforms}

- CONFIDENCE contributed to many challenges identified in the SRAs of the various platforms and helped to answer some, but not all questions;

- Furthermore CONFIDENCE has raised further research questions that have not been considered.

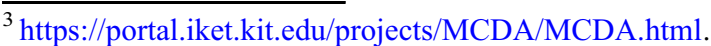

\section{Key messages from end users}

- How do we keep databases, in particular of radioecological models, up to date; does the IAEA compilation of data summarised in "TRS472" (https://www-pub.iaea.org/ $\mathrm{MTCD} /$ publications/PDF/trs472_web.pdf) require updating?

- The use of methods developed within CONFIDENCE might help IAEA to support member states in stakeholder engagement and societal investigations;

- Further research is needed to better understand the general public and provide better advise to them;

- Stakeholder panels are needed to consider not only the technical or scientific aspects (as can be considered in the simulation models) that improve the understanding or knowledge of the situation, but the complexity of the relationships among the actors involved in the decisionmaking confronted with their different views and preferences. It is necessary maintain an active network of stakeholders to assay the process of national dialogue and to be prepared for whatever event. In particular, international panels may help closing the gaps that could exist at national level;

- A lot of practical tools were developed within CONFIDENCE. There is the need for the operational community to have access to this knowledge;

- Need to maintain the tools and update them;

- Continuous training is important.

\section{Key messages from CONCERT and CONFIDENCE}

- Source term and meteorological uncertainties have been demonstrated to be of prime importance, but we are far from having a proper quantification of these uncertainties in an emergency context;

- Combination techniques for prognostic results and monitoring data should be improved;

- Citizen monitoring and monitoring strategies are important areas for future research;

- Soil-plant process-based models are worth pursuing;

- It is necessary to go further in the techniques of analysis of scenarios and in the participatory processes structured with the stakeholders as they are crucial tools to cope with the preparedness for response and post-accident recovery;

- CONFIDENCE recommendations highlighted the need to develop a comprehensive approach which not only relies on feedback following nuclear crises, but also considers experiences from other catastrophes (e.g. natural disaster, chemical and technological disaster, etc.). To that extent, new collaborations should be created;

- More in-depth research on citizens' potential response to nuclear emergency situations is needed;

- Empirical research on, and testing of effective methods for communication of uncertainties is the next step;

- Improve decision model, e.g. by combining with Case Based Reasoning, Multi Criteria Decision Analysis and Evolutionary Algorithms;

- Further develop and apply the training course "Use of uncertain information by decision makers at the various levels within the decision making process and its communication" based on the CONFIDENCE Dissemination workshop outcomes and materials on a regularly level complementary to the NERIS training courses. 
CONFIDENCE has achieved results that were regarded as important to enable the community to better deal with uncertainties in the decision-making process. Integration of some of the results in operational tools helps in further testing them under operational conditions. However, what is missing, but which is part of other H2020 research areas, is a large demonstration project. With such a demonstration project, one could collect all relevant stakeholders, explore the existing tools, refine them if needed and provide something at the end of the project that could be a standard for the whole of Europe.

Acknowledgement. The work described in this paper was conducted within the CONFIDENCE project which was part of the CONCERT project. This project has received funding from the Euratom research and training programme 20142018 under grant agreement No 662287.

Disclaimer (Art. 29.5 GA). This publication reflects only the author's view. Responsibility for the information and views expressed therein lies entirely with the authors. The European Commission is not responsible for any use that may be made of the information it contains.

\section{References}

Beresford NA, Barnett CL, Chaplow J, Lofts S, Wells C, Brown JE, Hosseini A, Thørring H, Almahayni T, Sweeck L, Guillén J, Lind O-C, Oughton DH, Salbu B, Teien H-C, Perez-Sánchez D, Real A. 2020. CONFIDENCE overview of improvements in radioecological human food chain models and future needs. Radioprotection 55(HS1). https://doi.org/10.1051/radiopro/2020019.

Bleher M, Gering F, Stöhlker U, Karhunen T, Nalbandyan-Schwarz A, Woda C, Mafodda A. 2020. Reduction of uncertainties in exposure assessment based on environmental monitoring data. Radioprotection 55(HS1). https://doi.org/10.1051/radiopro/ 2020016.

Charnock T, Andersson K, Trueba C, Montero M. 2020. Uncertainties confronting stakeholders and decision-makers in planning intervention in urban and agricultural scenarios in the transition phase of a radiological emergency. Radioprotection 55(HS1). https://doi.org/10.1051/radiopro/2020021.

Duranova T, Beresford NA, Perko T, Raskob W. 2020. Education and training activities in the Euratom CONFIDENCE project.
Radioprotection 55(HS1). https://doi.org/10.1051/radiopro/ 2020011.

Ehrhardt J, Weis A, Eds. 2000. RODOS: Decision support system for off-site nuclear emergency management in Europe, Final report of the RODOS project. European Commission, Brussels. Report EUR 19144, ISBN No. 92-828-9773-7, einschl. 2 CDs mit allen technischen Dokumenten des RODOS Systems.

French S, Haywood S, Oughton DH, Turcanu C. 2020. Different types of uncertainty. Radioprotection 55(HS1). https://efdoi.org/ 10.1051/radiopro/2020029.

Girarda S, Korsakissoka I, Mallet V. 2014. Screening sensitivity analysis of a radionuclides atmospheric dispersion model applied to the Fukushima disaster. Atmos. Environ. 95: 490-500.

Ievdin I, Trybushnyi D, Zheleznyak M, Raskob W. 2010. RODOS reengineering: aims and implementation details. Radioprotection 45 (5 Suppl.): 1S181-S189.

Ikonen ATK, Smith K, Robinson CA, De La Cruz I, Lindborg T, Thiry Y, Strand P, Norris S. 2012. Non-human biota assessments for geological disposal facilities - a study of the key uncertainties and importance for dose estimates. Radioprotection 46(6): S283-S288.

Leadbetter SJ, Andronopoulos S, Bedwell P, Chevalier-Jabet K, Geertsema G, Gering F, Hamburger T, Jones AR, Klein H, Korsakissok I, Mathieu A, Pázmándi T, Périllat R, Rudas C, Sogachev A, Szanto P, Tomas J, Twenhöfel C, de Vries H, Wellings J. 2020. Ranking uncertainties in atmospheric dispersion modelling following the accidental release of radioactive material. Radioprotection 55(HS1). https://doi.org/10.1051/radiopro/ 2020012.

NERIS SRA. 2019. NERIS strategic research agenda. Available from https://eu-neris.net/home/newsletters/217-new-version-of-theneris-sra-november-2019.html (Accessed 11/12/19).

Raskob W, Beresford NA, Duranova T, Korsakissok I, Mathieu A, Montero M, Mueller T, Turcanu C, Woda C. 2020. CONFIDENCE: Achievements and way forward. Radioprotection 55 (HS1). https://doi.org/10.1051/radiopro/2020010.

Tarsitano D, Semioschkina N, Voigt G. 2005. EVANET-TERRAevaluation and network of EC-decision support systems in the field of terrestrial radioecological research. Radioprotection 40 (Suppl. 1): S261-S268.

Turcanu C, Perko T, Baudé S, Hériard-Dubreuil G, Zeleznik N, Oughton DH, Tomkiv Y, Sala R, Oltra C, Tafili V, Benighaus L, Maitre M, Schneider T, Crouail P, Duranova T, Paiva I. 2020. Social, ethical and communication aspects of uncertainty management. Radioprotection 55(HS1). https://doi.org/10.1051/ radiopro/2020024.

Cite this article as: Raskob W, Beresford NA, Duranova T, Korsakissok I, Mathieu A, Montero M, Müller T, Turcanu C, Woda C. 2020. CONFIDENCE: project description and main results. Radioprotection 55(HS1): S7-S15 